\title{
Sperm factors related to failure of human in-vitro fertilization
}

\author{
C. Jeulin*, D. Feneux*, C. Serres*, P. Jouannet*, F. Guillet-Rosso†, \\ J. Belaisch-Allart $\dagger$, R. Frydman $\dagger \ddagger$ and J. Testart $\$$ \\ * Laboratoire d'Histologie-Embryologie, CHU, 94275 Le Kremlin-Bicêtre; † Service de \\ Gynécologie-Obstétrique, and $\ddagger I N S E R M U 187$, Hôpital Antoine Béclère, 92140 Clamart, France
}

\begin{abstract}
Summary. Two groups of men were retrospectively selected according to their observed success in in-vitro fertilization. Seminal and post-migration sperm samples from a low fertilization rate group ( $\leqslant 33 \%$ cleaved embryos) have been compared to results obtained from a high fertilization rate group $(\geqslant 66 \%)$. It was found that a low mean value of the amplitude of lateral sperm head displacement and an increased percentage of abnormal acrosomes were related to in-vitro fertilization failure. None of the individual sperm factors studied was found to determine in-vitro fertilization success with certainty; only when they were considered in combination was it possible to predict the likelihood of successful in-vitro fertilization of human oocytes.
\end{abstract}

\section{Introduction}

Although spermatozoa are usually selected by swim-up migration, and only a low number of motile spermatozoa are needed for successful in-vitro fertilization (Testart et al., 1985), failure of fertilization or cleavage is observed in $15-29 \%$ of cases showing normal semen characteristics (Edwards et al., 1984; Garcia et al., 1984; Trounson \& Wood, 1984; Belaisch-Allart et al., 1984). Such fertilization failure may be due to technical factors as well as to the quality of the gametes. In addition, it has been shown that the fertilization rate or the proportions of embryos undergoing cleavage decreases when the seminal sperm concentration, and/or the percentages of motility or normal morphology are reduced (Mahadevan \& Trounson, 1984; Edwards et al., 1984; Cohen et al., 1985).

In the present study a detailed analysis of semen samples, selected according to their success in in-vitro fertilization ('low success group': $\leqslant 33 \%$ of cleaved embryos, and 'high success group': $\geqslant 66 \%$ fertilization rate) has been made. Particular reference was made to the movement characteristics and detailed morphology of the spermatozoa both in liquefied semen and after migration.

\section{Materials and Methods}

\section{Patient population}

Two groups of men were retrospectively selected according to their observed success in in-vitro fertilization. The female partners were aged between 26 and 40 years and had had 1 to 3 attempts at in-vitro fertilization between September 1982 and October 1983. Ovarian stimulation was achieved by clomiphene citrate in combination with human menopausal gonadotrophin as described by Testart et al. (1985). The in-vitro fertilization procedures were as described previously (Testart, Lassalle, Frydman \& Belaisch, 1983). 
Table 1. In-vitro fertilization characteristics of the high and low success groups (values in parentheses denote the individual patient ranges)

Low in-vitro fertilization

\section{No. of patients}

No. of cycles

No. of mature oocytes

No. of cleaved embryos

$\%$ cleaved embryos rate

$\begin{array}{cl}8 & \\ 17 & (1-3) \\ 31 & (2-8) \\ 4 & (0-2) \\ 12 \cdot 0 & (0-33)\end{array}$

High in-vitro fertilization

rate

$\begin{array}{ll}9 & \\ 17 & (1-3) \\ 41 & (2-8) \\ 33 & (2-6) \\ 80 \cdot 5 & (67-100)\end{array}$

Before acceptance for the in-vitro fertilization programme the semen of all the men had been judged to be of acceptable quality: $>20 \%$ motile spermatozoa and able to maintain sperm motility after $24 \mathrm{~h}$ of incubation under the conditions used for preincubation of the spermatozoa (Testart $e t$ al., 1983).

While the numbers of mature oocytes collected per patient, as well as the number of treatment cycles, were similar in both groups (Table 1), in the 'low success' group the mean proportion of embryos undergoing cleavage was only $12 \%$, while $80.5 \%$ of embryos in the 'high success' group showed cleavage.

\section{Sperm characteristics}

Semen analysis. One ejaculate per patient was produced at the laboratory by masturbation within 3 months of his last in-vitro fertilization attempt. The usual semen characteristics were analysed as described by Jouannet (1984).

Sperm motility. Photomicrography was carried out at room temperature on $10 \mu$ droplets of sperm suspension under $22 \times 32 \mathrm{~mm}$ coverslips. These preparations had a depth of $\sim 15 \mu \mathrm{m}$. Ten (1 sec) exposures were taken on Kodak Panatomic X $35 \mathrm{~mm}$ film under darkground illumination (Overstreet, Katz, Hanson \& Fonseca, 1979) using a Reichert Univar microscope with $\times 25$ objective. Developed filmstrips were analysed, at a final magnification of $\times 500$, by a semi-automated method using a Quantimet 720 PDP 11/34 image analysis system (D. Schoëvaert-Brossault \& C. Jeulin, unpublished method). Spermatozoa were classified as immotile, non-progressively motile, or progressively motile. 'Non-progressive' included all spermatozoa showing any kind of flagellar or head movement with a progression velocity $<10 \mu \mathrm{m} / \mathrm{sec}$. For each progressively motile spermatozoon its velocity of progression along its trajectory path $(\mathrm{Vp})$ and its amplitude of lateral head displacement (Ah) were measured (Fig. 1).

Sperm morphology. Permanent stained smears (Shorr staining for hormonal cytodiagnosis; Merck, Darmstadt, FRG) were prepared from semen and post-migration samples. All slides were randomized and coded before scoring by the same observer. From each slide 100 spermatozoa were assessed under oil immersion at a magnification of $\times 1000$ using bright-field illumination. The detailed morphological classification was made according to David, Bisson, Czyglik, Jouannet \& Gernigon (1975). This method distinguishes 7 types of head abnormality, 2 types of midpiece abnormality and 4 types of flagellar abnormality by multiple-entry scoring. Special attention was paid to amorphous heads to characterize the morphological abnormalities of the acrosome (Fig. 2).

Acrosomal integrity. The triple staining method (Talbot \& Chacon, 1981; Talbot \& Dudenhausen, 1981) was used to assess the integrity of the acrosome in seminal spermatozoa. The acrosome reaction per se during the preincubation period was not evaluated. Three staining patterns were therefore considered: (1) live cells with 'intact' acrosome = 'stained acrosome'; (2) 
live cells without a stained acrosome region; and (3) dead spermatozoa. Slides were examined at $\times 1000$ magnification under bright-field illumination by each of two observers (C.S. and D.F.). Microscope fields were selected at random and 200 spermatozoa were counted. Final results were the average of those obtained by the two observers.

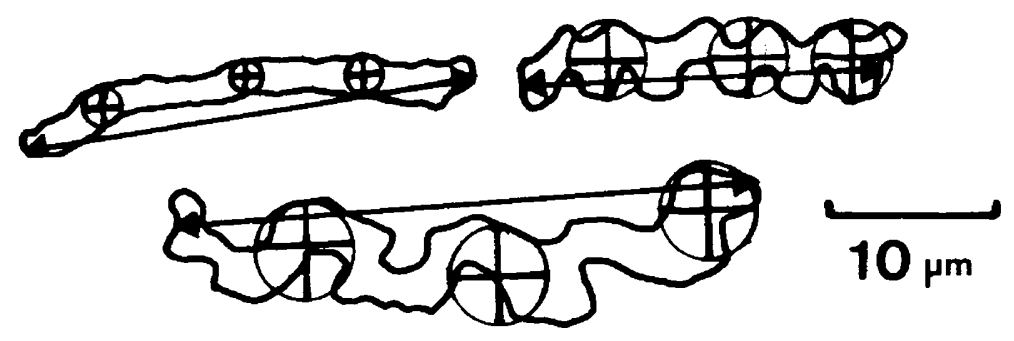

Fig. 1. Diagrammatic representation of the semi-automated analysis of tracings from 1-sec timed exposure filmstrips. Black arrows indicate how $\mathrm{Vp}(\mu \mathrm{m} / \mathrm{sec})$ is measured. The diameters of three circles are measured and their mean diameter is $\mathrm{Ah}(\mu \mathrm{m})$.

(a)

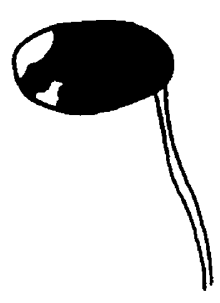

(b)

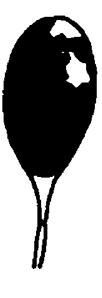

(c)

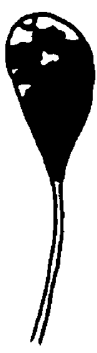

(d)

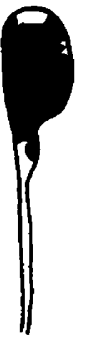

(e)

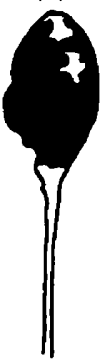

(f)

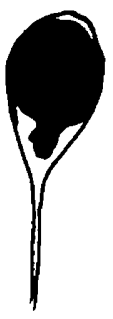

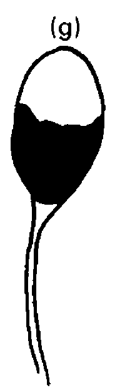

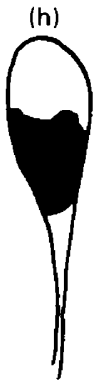

(i)

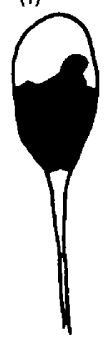

Fig. 2. Diagrammatic representation of Shorr-stained spermatozoa with an abnormal acrosome $(a, b, c)$, with an amorphous head and abnormal acrosome $(d, e, f)$, and with a normal head and normal acrosome $(\mathrm{g}, \mathrm{h}, \mathrm{i})$. 
Nuclear maturation. Immature nuclear protein was revealed by aniline blue staining as described by Terquem \& Dadoune (1983). After two successive washings $(600 \mathrm{~g}$ for $10 \mathrm{~min})$ in phosphate-buffered saline (PBS, $1.9 \mathrm{~mm}-\mathrm{NaH}_{2} \mathrm{PO}_{4} \mathrm{H}_{2} \mathrm{O}, 8 \cdot 1 \mathrm{~mm}-\mathrm{Na}_{2} \mathrm{HPO}_{4} 2 \mathrm{H}_{2} \mathrm{O}, 145.4 \mathrm{~mm}$ $\mathrm{NaCl}$ ), the resuspended cells were spread onto glass slides. Smears were fixed for $30 \mathrm{~min}$ using $3 \%$ glutaraldehyde in PBS and stained in 5\% aqueous aniline blue (CI 42 755: Prolabo, Paris) with 4\% acetic acid (pH 3.5). A rapid mounting medium (Entellan: Merck, Darmstadt) was used to preserve the staining of the smears.

Slides were examined at $\times 1000$ magnification under bright-field illumination by each of two observers (C.J. and C.S.). Microscope fields were selected at random and 200 spermatozoa were counted. Final results were the average of those obtained by the two observers.

Acidic aniline blue is known to stain the chromatin of early spermatids strongly (McKay, 1962). Terquem \& Dadoune (1983) demonstrated the variable ability of ejaculated human spermatozoa to take up aniline blue (non-stained = mature nucleus, stained or partly stained = immature nucleus).

\section{Sperm preparation}

Measurements were made on spermatozoa in liquified semen and also in a selected sperm population prepared according to the procedure used in the in-vitro fertilization programme. Briefly, two $0.5 \mathrm{ml}$ samples of semen were diluted with $9 \mathrm{ml}$ Tyrode's medium $(137 \mathrm{~mm}-\mathrm{NaCl}$, $2.7 \mathrm{~mm}-\mathrm{KCl}, 1.4 \mathrm{~mm}-\mathrm{CaCl}_{2}, 0.5 \mathrm{~mm}-\mathrm{MgCl}_{2}, 0.3 \mathrm{~mm}-\mathrm{NaH}_{2} \mathrm{PO}_{4} 2 \mathrm{H}_{2} \mathrm{O}, 12 \mathrm{~mm}-\mathrm{NaHCO}_{3}, 5.5 \mathrm{~mm}-$ glucose) and centrifuged for $5 \mathrm{~min}$ at $600 \mathrm{~g}$. The supernatants were removed, the pellets resuspended and washed again in $5 \mathrm{ml}$ Tyrode's. Then $1 \mathrm{ml} \mathrm{B} 2$ medium (Api-System, La Balme-lesGrottes, France) was overlayered onto the final pellet. At the end of the migration period $(1 \mathrm{~h}$ at ambient temperature) the upper fraction (usually $0.6 \mathrm{ml}$ ) of the medium layer was removed with a Pasteur pipette. Samples were taken for analysis and the remainder incubated at $37^{\circ} \mathrm{C}$ in a humidified atmosphere of $5 \% \mathrm{CO}_{2}$ in air for a period of $4 \mathrm{~h}$.

Table 2. Sperm characteristics measured before (semen) and after migration into B2 medium (mean values \pm s.d.) in the low and high fertilization rate groups

\begin{tabular}{|c|c|c|c|c|}
\hline & \multicolumn{2}{|c|}{ Low IVF success group } & \multicolumn{2}{|c|}{ High IVF success group } \\
\hline & Semen & After migration & Semen & After migration \\
\hline No. of men & 8 & 8 & 9 & 9 \\
\hline Volume $(\mathrm{ml})$ & $2.9 \pm 1.4$ & - & $3.7 \pm 1.8$ & - \\
\hline Vitality $(\%)$ & $72 \cdot 9 \pm 15 \cdot 2$ & - & $74 \cdot 2 \pm 13 \cdot 3$ & - \\
\hline Concentration $\left(\times 10^{6} / \mathrm{ml}\right)$ & $51 \cdot 8 \pm 33 \cdot 2$ & $4 \cdot 0 \pm 3 \cdot 4$ & $92 \cdot 7 \pm 50 \cdot 4$ & $4.9 \pm 4 \cdot 8$ \\
\hline Progressive motility $(\%)$ & $39 \cdot 4 \pm 20 \cdot 2$ & $44 \cdot 2 \pm 9 \cdot 4$ & $37 \cdot 1 \pm 14 \cdot 9$ & $59 \cdot 5 \pm 22 \cdot 1$ \\
\hline Non-progressive motility (\%) & $14.4 \pm 7.8$ & $19.9 \pm 6.8$ & $10 \cdot 7 \pm 3.7$ & $13 \cdot 4 \pm 6 \cdot 1$ \\
\hline $\mathrm{Vp}(\mu \mathrm{m} / \mathrm{sec})$ & $24.9 \pm 4.7$ & $32 \cdot 6 \pm 5 \cdot 7^{\mathrm{a}}$ & $24.8 \pm 6.7$ & $26 \cdot 5 \pm 4 \cdot 6^{\mathrm{a}}$ \\
\hline $\mathrm{Ah}(\mu \mathrm{m})$ & $6 \cdot 6 \pm 1 \cdot 3^{\mathrm{b}}$ & $8.4 \pm 1.1$ & $8 \cdot 0 \pm 1 \cdot 2^{b}$ & $9.0 \pm 0.9$ \\
\hline $\begin{array}{l}\text { Morphologically normal } \\
\text { spermatozoa }(\%)\end{array}$ & $31 \cdot 7 \pm 17 \cdot 6^{c}$ & $31 \cdot 9 \pm 15 \cdot 7^{d}$ & $56 \cdot 0 \pm 14 \cdot 1^{c}$ & $64 \cdot 4 \pm 20 \cdot 1^{d}$ \\
\hline $\begin{array}{l}\text { Live spermatozoa with } \\
\text { stained acrosomes }(\%)\end{array}$ & $49 \cdot 5 \pm 17 \cdot 8^{e}$ & - & $76 \cdot 3 \pm 12 \cdot 6^{\mathrm{e}}$ & - \\
\hline $\begin{array}{l}\text { Sperm nuclei stained } \\
\text { with aniline blue }(\%)\end{array}$ & $27 \cdot 8 \pm 13 \cdot 3^{f}$ & $28 \cdot 0 \pm 19 \cdot 9$ & $14 \cdot 5 \pm 5 \cdot 1^{\mathrm{f}}$ & $11 \cdot 8 \pm 8 \cdot 5$ \\
\hline
\end{tabular}

$\mathrm{Vp}=$ velocity of progression; $\mathrm{Ah}=$ amplitude of lateral head displacement.

Significant differences between the two groups indicated: $\mathrm{b}, P=0.05 ; \mathrm{a}, P<0.05 ; \mathrm{c}, \mathrm{d}, \mathrm{e}, \mathrm{f}, P<0.01$ by the Kruskall-Wallis non-parametric test. 


\section{Statistical analysis}

Non-parametric statistics were used throughout the study. The Kruskall-Wallis test was used to compare results between the two groups of men, and the Wilcoxon T paired ranks test for comparisons between seminal and post-migration samples. Relationships between in-vitro fertilization success rate and sperm characteristics were examined by Spearman rank correlation coefficients.

Multiple linear regression by groups before and after migration was performed using various combinations of the following 5 characteristics; percentage of morphologically normal spermatozoa; percentage of abnormal acrosomes; percentage of stained nuclei; and the mean values of $\mathrm{Ah}$ and $\mathrm{Vp}$. This multiple linear regression procedure was described by Armitage (1971) and used the BMDP statistical package (Dixon, 1981).

\section{Results}

\section{Semen characteristics of the high and low success groups}

Semen samples from the two groups of men showed no significant differences with respect to the following sperm characteristics: volume; $\mathrm{pH}$; sperm concentration; percentage motility; or mean $\mathrm{Vp}$ (Table 2). However, spermatozoa from men in the low success group exhibited smaller mean $\mathrm{Ah}$ values. In addition, their mean percentage of morphologically normal cells was reduced, particularly with respect to the proportion of live spermatozoa with stained or 'intact' acrosomes. Among all the morphological abnormalities, deformed acrosomes (Fig. 2) were the most frequent. In the low success group the mean percentage of spermatozoa with an abnormal acrosome was higher (35.2 vs $19.8 \%$ in semen; $P<0.02$, as was the mean percentage of sperm nuclei stained with aniline blue ('immature' nuclei; see Table 2).

\section{Differences between seminal and post-migration sperm populations}

Obvious differences were found between the initial semen and post-migration samples. The mean percentages of progressive and non-progressive motility were both increased in the low success group $(P<0.05$ and $P<0.01$, respectively, Table 2$)$. Swim-up migration produced a significant $(P<0.001)$ improvement but only in the mean percentage of progressive motility in the high success group. However, in both groups, the progressive post-migration spermatozoa exhibited a greater $\mathrm{Vp}(P<0.01)$ and greater $\mathrm{Ah}(P<0.01)$ than they did in the initial semen samples. The proportion of morphologically normal cells was increased only in the high success group (Table 2 ). After migration, the mean ( \pm s.d.) percentage of spermatozoa with an abnormal acrosome was reduced in the high success group $(16.0 \pm 13.8 \mathrm{vs} 19.8 \pm 12.8 \%, P<0.05)$ but increased in the low success group $(46 \cdot 6 \pm 18 \cdot 5$ vs $35 \cdot 2 \pm 12 \cdot 2 ; P<0 \cdot 01)$.

Comparison between seminal and post-migration populations with regard to the percentage of stained acrosomes was not possible since all post-migration samples could not be analysed with the technique used. In 10 samples that could be evaluated, the mean percentage of sperm with intact acrosomes was $53.2 \pm 31.8$ in the post-migration group compared with $74.6 \pm 11.8$ in semen.

Consequently, post-migration spermatozoa exhibited new differences between the two groups. The low success group was characterized by an apparent greater mean value of $\mathrm{Vp}$, and an overall equivalent mean percentage of morphologically normal spermatozoa but with an increased incidence of deformed acrosomes.

Post-incubation samples showed no differences between the two groups of men with respect to the mean values of $\mathrm{Vp}(31.4 \pm 8.1$ s.d. $v s 27.7 \pm 3.7 \mu \mathrm{m} / \mathrm{sec})$ or $\mathrm{Ah}(8.5 \pm 0.8 v \mathrm{~s} 8.8 \pm 0.6 \mu \mathrm{m})$. 
Table 3. Correlation matrix between various sperm characteristics in the semen and post-migration samples

\begin{tabular}{lcccc}
\hline & $\begin{array}{c}\text { Abnormal } \\
\text { acrosomes }\end{array}$ & $\begin{array}{c}\text { Stained } \\
\text { acrosomes }\end{array}$ & $\begin{array}{c}\text { Immature } \\
\text { nuclei }\end{array}$ & $\begin{array}{c}\text { Normal } \\
\text { forms }\end{array}$ \\
\hline Semen & - & & & \\
Abnormal acrosomes (\%) & -0.34 & - & & \\
Stained acrosomes (\%) & $0.47^{\mathrm{a}}$ & $-0.53^{\mathrm{a}}$ & - & - \\
Immature nuclei (\%) & $-0.87^{\mathrm{b}}$ & $0.59^{\mathrm{a}}$ & $-0.52^{\mathrm{a}}$ & \\
Normal forms (\%) & & & & \\
After migration & - & n.d. & - & - \\
Abnormal acrosomes (\%) & $0.47^{\mathrm{a}}$ & n.d. & -0.43 & - \\
Immature nuclei (\%) & $-0.93^{\mathrm{b}}$ & n.d. & - & \\
Normal forms (\%) & & & & \\
\hline
\end{tabular}

Significant values of the Spearman rank correlation coefficient are denoted by superscript letters: a, $P<0.05 ; \mathrm{b}, P<0.01$.

Table 4. Correlation matrix between various sperm characteristics and the success of in-vitro fertilization

\begin{tabular}{lcc}
\hline & \multicolumn{2}{c}{ IVF success } \\
\cline { 2 - 3 } Characteristics & Semen & After migration \\
\hline Abnormal acrosomes $(\%)$ & $-0.72^{\mathrm{b}}$ & $-0.72^{\mathrm{b}}$ \\
Stained acrosomes $(\%)$ & $0.62^{\mathrm{b}}$ & $-\dagger$ \\
Immature nuclei $(\%)$ & -0.42 & -0.36 \\
Normal forms $(\%)$ & $0.71^{\mathrm{b}}$ & $0.65^{\mathrm{b}}$ \\
Mean $\mathrm{Vp}(\mu \mathrm{m} / \mathrm{sec})$ & 0.19 & -0.38 \\
Mean $\mathrm{Ah}(\mu \mathrm{m})$ & $0.51^{\mathrm{a}}$ & 0.35 \\
\hline
\end{tabular}

† Not determined.

Significant values of the Spearman rank correlation coefficient are denoted by superscript letters: $\mathrm{a}, P<0.05 ; \mathrm{b}, P<0.01$.

\section{Correlations between the various sperm characteristics}

Correlations between the various sperm characteristics in the seminal and post-migration populations are shown in Table 3 . The highest correlations (negative) were between the percentage normal forms and the proportion of spermatozoa with abnormal acrosomes as indicated by Shorr staining $(r=-0.87$ in the semen, and $r=-0.93$ after migration, both $P<0.01)$. Other significant correlations were found between the incidences of immature nuclei and acrosomal abnormalities $(P<0.05$ in the semen and after migration), as well as between the percentage normal forms and nuclear maturation $(P<0.05$ only in the semen $)$.

\section{Correlations between sperm characteristics and the in-vitro fertilization success rate}

These correlations were determined by calculation of Spearman's rank correlation coefficients (Table 4). The most significant correlations concerned the percentage normal forms (Fig. 3a), the incidence of abnormal acrosomes (Fig. 3b), the proportion of live spermatozoa with stained ('intact') acrosomes (Fig. 3c), and the mean Ah values (Fig. 3d).

The results of the multiple linear regression analysis are presented in Table 5 . None of the 5 characteristics, when considered in isolation, was able to predict in-vitro fertilization success. However, from this analysis it was apparent that the incidence of abnormal acrosomes (from Shorr-stained smears) and the mean $\mathrm{Ah}$ values gave a highly significant discrimination between the two groups of men using seminal $(P<0.001)$ or post-migration $(P<0.002)$ values. Indeed, none of 
the low success group showed $<30 \%$ abnormal acrosomes and mean Ah values of $\geqslant 7 \cdot 5 \mu \mathrm{m}$ in the semen, or $<30 \%$ abnormal acrosomes and mean $\mathrm{Ah}$ values of $\geqslant 8.5 \mu \mathrm{m}$ after migration (Table 6 ). Conversely, in individuals in which all these conditions were satisfied, there was always a high level of fertilization. Reduction in any one characteristic below the limiting values resulted in an apparently increased risk of a low fertilization rate.
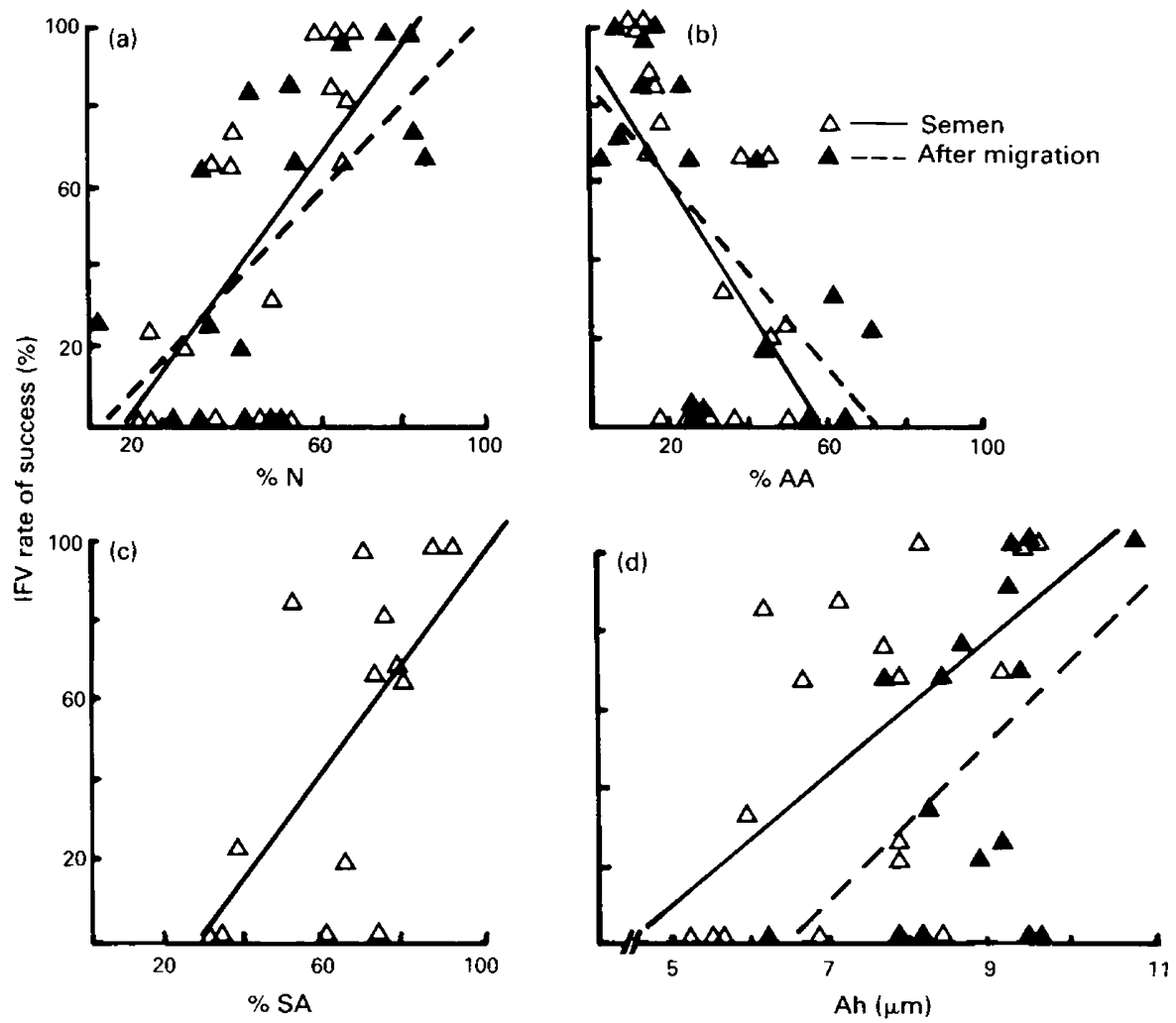

Fig. 3. Relationships between the in-vitro fertilization (IVF) success rate and (a) the percentage of morphologically normal spermatozoa $(\mathrm{N})(n=17)$, (b) the percentage of spermatozoa with abnormal acrosomes (AA) $(n=17)$, (c) the percentage of live spermatozoa with stained acrosomes (SA) $(n=14)$, and (d) the mean amplitude of the lateral head displacement (Ah) ( $n=17$ in semen, and $n=16$ after migration).

Table 5. Multiple linear regression between sperm characteristics and the IVF success rate

Combinations of sperm characteristics

Significance of differences between the two groups

$\mathrm{N}=$ morphologically normal spermatozoa; $\mathrm{AA}=$ abnormal acrosomes; $\mathrm{SN}=$ stained nuclei; $\mathrm{Ah}=$ amplitude of head movement; $V \mathbf{P}=$ velocity of progression. 
Table 6. Influence of the percentage of abnormal acrosomes (AA) and the mean value of the amplitude of the lateral head displacement $(\mathrm{Ah})$ on the IVF success rate

\begin{tabular}{lcc}
\hline & Low IVF success $(\leqslant 33 \%)$ & High IVF success $(\geqslant 66 \%)$ \\
\hline Semen samples & & \\
$\mathrm{AA} \geqslant 30 \%$ and $\mathrm{Ah}<7.5 \mu \mathrm{m}$ & 2 & 0 \\
$\mathrm{AA} \geqslant 30 \%$ or $\mathrm{Ah}<7.5 \mu \mathrm{m}$ & 6 & 4 \\
$\mathrm{AA}<30 \%$ and $\mathrm{Ah} \geqslant 7.5 \mu \mathrm{m}$ & 0 & 5 \\
Post-migration samples & & \\
$\mathrm{AA} \geqslant 30 \%$ and $\mathrm{Ah}<8.5 \mu \mathrm{m}$ & 1 & 1 \\
$\mathrm{AA} \geqslant 30 \%$ or $\mathrm{Ah}<8.5 \mu \mathrm{m}$ & 7 & 6 \\
$\mathrm{AA}<30 \%$ and $\mathrm{Ah} \geqslant 8.5 \mu \mathrm{m}$ & 0 & \\
\hline
\end{tabular}

\section{Discussion}

The literature regarding the influence of sperm factors, usually the sperm concentration and the percentages of motile and/or morphologically normal spermatozoa, on in-vitro fertilization success is confusing. Since pregnancies have been achieved with semen showing abnormal, or even pathological by classical criteria, characteristics it has been assumed that in-vitro fertilization could be used as a treatment for male infertility even though no controlled studies have been carried out. The reports of Edwards et al. (1984) and Cohen et al. (1984) that a majority of men with abnormal semen were able to fertilize human oocytes in vitro have strengthened this opinion. However, explanations are rarely given for the observed failures of fertilization in vitro.

The results of the present study have revealed that in-vitro fertilization failure cannot be explained by the alteration of any single sperm characteristic, although consideration of several characteristics in association may permit prediction of failure or success. Optimum discrimination appears to involve several variables of sperm morphology and sperm movement of which the percentage of abnormal acrosomes and lateral displacement of the moving sperm head were the most significant.

Such a relationship between sperm morphology and the fertilization of human oocytes in vitro was reported by Mahadevan, Trounson \& Leeton (1983) and Mahadevan \& Trounson (1984) and has been confirmed by Cohen et al. (1985). Therefore, decreased sperm quality may reduce the chance of a couple achieving pregnancy after in-vitro fertilization. In addition Rogers et al. (1983) found a correlation between sperm morphology and the penetration of zona pellucida-free hamster oocytes in vitro.

Unfortunately, most commonly used morphological classification schemes use only a singleentry scoring system, and in consequence some abnormalities will be underestimated when they occur in association with other defects of that, or other parts, of the spermatozoon. For this reason these earlier studies were only able to consider the 'percentage normal forms'. Use of a more sensitive morphological classification scheme, based upon multiple-entry scoring as described by David et al. (1975), would therefore seem appropriate, and was employed in the present study.

It would, however, be prudent to emphasize that light microscopical staining of the acrosome does not permit accurate determination of the state of the acrosome (Mortimer, 1981), which would require complementary ultrastructural analysis. Furthermore, it may not be the apparent abnormal acrosomal morphology that is prejudicial to fertilization in vitro. There is a relationship between acrosomal abnormalities and the nuclear maturity of the spermatozoa (Table 3), as was reported by Bisson (1981) who found that $70 \%$ of heads that were amorphous when examined by transmission electron microscopy showed both nuclear and acrosomal abnormalities. Spermatozoa having amorphous heads associated with abnormal post-acrosomal sheaths showed very low rates of penetration in zona-free hamster oocytes (A. M. Courtot, D. Escalier, P. Jouannet \& G. David) (unpublished data). 
In the present study, the percentage of motile spermatozoa in the patients' semen was used as a selection criterion for in-vitro fertilization candidates (see 'Materials \& Methods'), and no difference between the high and low success groups was found with respect to this characteristic. However, more precise criteria of sperm movement, particularly the Ah value which was reduced in the low success group, did reveal differences (Table 2). Other studies have related Ah values to sperm penetration into cervical mucus and the success of the zona-free hamster egg penetration test. Spermatozoa with a very low Ah value show a reduced ability to penetrate human cervical mucus in vitro (Feneux, Serres \& Jouannet, 1985). This flagellar dyskinesia was determined as being related to abnormal periaxonemal structures which induce an abnormal development of the wave along the sperm tail and a low flagellar beat efficiency of the cell (Feneux et al., 1985; Serres, Feneux \& Jouannet, 1985). The motility pattern of human spermatozoa in semen and especially the lateral head displacement has been shown to be highly correlated with their potential for bovine cervical mucus penetration but poorly correlated with their ability to fuse with zona-free hamster oocytes (Aitken, Sutton, Warner \& Richardson, 1985). No measurements of Ah values in semen have been reported in relation to the in-vitro fertilizing ability of human spermatozoa. These previous observations and our results emphasize that the small amplitude of lateral head displacement, which may indirectly reflect the flagellar beat efficiency, appears to be a critical factor whenever the generation of shearing forces is involved, as in sperm penetration of cervical mucus or their ability to penetrate the cumulus oophorus and the zona pellucida. However, penetration of zona-free hamster ova can be achieved independently of the sperm propulsive forces even in the absence of sperm motility (Aitken, Ross \& Lees, 1983). However, Aitken, Best, Richardson, Djahanbakhch \& Lees (1982a), \& Aitken et al. (1982b) reported that, after capacitation, a mean Ah value of $<10 \mu \mathrm{m}$ was correlated with fertilizing capacity in the zona-free hamster egg penetration test. Unfortunately, since the temperature at which the sperm movement characteristics were determined differed in these studies and the present study, and the polaroid photomicrography system is of poor precision in comparison to the present technique, it is not possible to reach any conclusion as to the relationship between the Ah measurements in the two systems. However, all samples in the present study did show mean $A h$ values of $<10 \mu \mathrm{m}$.

The effects of swim-up migration and in-vitro incubation upon the sperm movement characteristics ( $\%, \mathrm{Vp}$ and $\mathrm{Ah}$ ) were comparable to those described by Mortimer, Courtot, Giovangrandi, Jeulin \& David (1984). However, while the spermatozoa from the low success group exhibited a greater mean $\mathrm{Vp}$ value after migration than in seminal plasma, there was no equivalent change in the high success group. From the mean values (Table 2) it is evident that, even ignoring the reduction in $\mathrm{Vp}$ that would have been present had it been determined at ambient temperature, the mean $\mathrm{Vp}$ values exhibited by the men in the present study would appear to be normal according to the criteria given by Aitken et al. (1982a, b).

In conclusion, sperm morphology (particularly acrosomal morphology) and sperm movement (particularly the $\mathrm{Ah}$ value) are important discriminators with respect to in-vitro fertilization success, especially in post-migration sperm populations, although even in semen it is apparently possible to distinguish between samples that will show normal fertilization and those that will show an increased likelihood of reduced fertilization. Whether the reduced fertilization rate seen in the low success group may be improved by modification of the sperm preparation and/or preincubation conditions, or by simply using larger concentrations of these spermatozoa and the oocytes remains unknown. It would also be of interest to know which acrosomal abnormalities are not prejudicial to the fertilization of human oocytes.

We thank Mrs J. De Bée and A. Soumah for technical assistance; Mrs M. L. Guihard and Dr A. Spira for statistical advice; Dr D. Mortimer for the English translation and critical discussion; and Mrs A. Lorent and Mrs V. Barrey for typing the manuscript. This research was supported by a grant from the Ministère de la Recherche et de l'Industrie (M.R.I.), contract no. 83C-0668. 


\section{References}

Aitken, R.J., Best, F.S.M., Richardson, D.W., Djahanbakhch, O. \& Lees, M.M. (1982a) The correlates of fertilizing capacity in normal fertile men. Fert. Steril. 38, 68-76.

Aitken, R.J., Best, F.S.M., Richardson, D.W., Djahanbakhach, O., Mortimer, D., Templeton, A.A. \& Lees, M.M. (1982b) An analysis of sperm function in cases of unexplained infertility: conventional criteria, movement characteristics, and fertilizing ability. Fert. Steril. 38, 212-221.

Aitken, R.J., Ross, A., Lees, M.M. (1983) Analysis of sperm function in Kartagener's syndrome. Fert. Steril. 40, 696-698.

Aitken, R.J., Sutton, M., Warner, P. \& Richardson, D.W. (1985) Relationship between the movement characteristics of human spermatozoa and their ability to penetrate cervical mucus and zona free hamster oocytes. J. Reprod. Fert. 73, 441- 449.

Armitage, P. (1971) Multiple Regression in Groups in Statistical Methods in Medical Research, p. 320. Ed. P. Armitage. Blackwell Scientific Publications, Oxford.

Belaisch-Allart, J.C., Frydman, R., Testart, J., GuilletRosso, F., Lassalle, B., Volante, M. \& Papiernik, E. (1984) In vitro fertilization and embryo transfer program in Clamart, France. J. In Vitro Fertil. Embryo Trans. 1, 51-55.

Bisson, J.P. (1981) Apport de la microscopie électronique de transmission dans le bilan de l'infertilité masculine. In Human Fertility Factors, pp. 107-111. Eds A. Spira \& P. Jouannet. INSERM, Paris.

Cohen, J., Fehilly, C.B., Fishel, S.B., Edwards, R.G., Hewitt J., Rowland, G.F., Steptoe, P.C. \& Webster, J. (1984) Male infertility successfully treated by in vitro fertilization. Lancet 1, 1239-1240.

Cohen, J., Edwards, R., Fehilly, C., Fischel, S., Hewitt, J., Purdy, J., Rowland, G., Steptoe, P. \& Webster, J. (1985) In vitro fertilization: a treatment for male infertility. Fert. Steril. 43, 422-432.

David, G., Bisson, J.P., Czyglik, F., Jouannet, P. \& Gernigon, C. (1975) Anomalies morphologiques du spermatozoïde humain. 1. Proposition pour un système de classification. J. Gynaec. Obstet. Biol. Reprod. 4 (Suppl. 1), 17-43.

Dixon, W.J. (Ed.) (1981) Multiple Linear Regression. B.M.D.P. Statistical Software, Department of Biomathematics, University of California Press, Berkeley.

Edwards, R.G., Fishel, S.B., Cohen, J., Fehilly, C.B., Purdy, J.M., Slater, J.M., Steptoe, P.C. \& Webster, J.M. (1984) Factors influencing the success of in vitro fertilization for alleviating human infertility. $J$. In Vitro Fertil. Embryo Trans. 1, 3-23.

Feneux, D., Serres, C. \& Jouannet P. (1985) Sliding spermatozoa: a dyskinesia responsible for human infertility? Fert. Steril. 44, 508-511.

Garcia, J., Acosta, A., Andrews, M.C., Jones, G.S., Jones, H.W., Mantzavinos, T. Mayer, J., Mac Dowell, J., Sandow, B., Veeck, L., Whibley, T., Wilkes, C. \& Wright, G. (1984) In vitro fertilization in Norfolk, Virginia, 1980-1983. J. In Vitro Fertil. Embryo Trans. 1, 2428.
Jouannet, P. (1984) Exploration du testicule exocrine. In Médecine de la Reproduction Masculine, pp. 211-228. Eds G. Schaison, P. Bouchard, J. Mahoudeau \& F. Labrie. Flammarion Médecine/Sciences, Presses Université, Montréal.

McKay, R.B. (1962) An investigation of the anomalous staining of chromatin by the acid dyes, methyl blue and aniline blue. Q. Il microsc. Sci. 103, 519-530.

Mahadevan, M.M. \& Trounson, A.O. (1984) The influence of seminal characteristics on the success rate of human in vitro fertilization. Fert. Steril. $\mathbf{4 2}$, $400-405$.

Mahadevan, M.M., Trounson, A.O. \& Leeton, J.F. (1983) The relationship of tubal blockage, infertility of unknown cause, suspected male infertility and endometriosis to success of in vitro fertilization and embryo transfer. Fert. Steril. 40, 755-762.

Mortimer, D. (1981) The assessment of human sperm morphology in surface replica preparations for transmission electron microscopy. Gamete Res. 4, 113-119.

Mortimer, D., Courtot, A.M., Giovangrandi, Y., Jeulin, C. \& David, G. (1984) Human sperm motility after migration into, and incubation in, synthetic media. Gamete Res. 9, 131-144.

Overstreet, J.W., Katz, D.F., Hanson, F.W. \& Fonseca, J.R. (1979) A simple inexpensive method for objective assessment of human sperm movement characteristics. Fert. Steril. 31, 162-172.

Rogers, B.J., Bentwood, B.J., Campen, H.V., Helmbrecht, G., Soderdahl, D. \& Hale, R.W. (1983) Sperm morphology assessment as an indicator of human fertilizing capacity. J. Androl. 4, 119-125.

Serres, C., Feneux, D. \& Jouannet, P. (1985) Abnormal distribution of the periaxonemal structures in a human sperm flagellar dyskinesia. Cell Motility (in press).

Talbot, P. \& Chacon, R.S. (1981) A triple stain technique for evaluating normal acrosome reactions of human sperm. J. exp. Zool. 215, 201-208.

Talbot, P. \& Dudenhausen, E. (1981) Factors affecting triple staining of human sperm. Stain Technol. 56, 307-309.

Terquem, A. \& Dadoune, J.P. (1983) Aniline blue staining of human spermatozoon chromatin. Evaluation of nuclear maturation. In The Sperm Cell, pp. 249-252. Ed J. André. Martinus Nijhoff, The Hague.

Testart, J., Lassalle, B., Frydman, R. \& Belaisch, J.C. (1983) A study of factors affecting the success of human fertilization in vitro. II. Influence of semen quality and oocyte maturity on fertilization and cleavage. Biol. Reprod. 28, 425-431.

Testart, J., Lefèvre, B., Castanier, M., Belaisch-Allart, J., Guillet-Rosso, F. \& Frydman, R. (1985) Comparative effect of clomiphene and clomiphene/hMG on the preovulatory follicles and fertilizability of the oocyte. Ann. N.Y. Acad. Sci. 442, 128-139.

Trounson, A. \& Wood, C. (1984) In vitro fertilization results, 1979-1982, at Monash University, Queen Victoria, and Epworth Medical Centres, J. In Vitro Fertil. Embryo Trans. 1, $42-47$.

Received 7 August 1985 